\title{
Análise do uso da informação para tomada de decisão gerencial em gestão de pessoas: estudo de caso em uma instituição bancária
}

Thais Carrier Mendonça

Mestre em Ciência da Informação. Bacharel em Biblioteconomia pela Universidade Federal de Santa Catarina.

Gregório Varvakis

Professor Doutor do Departamento de Gestão do Conhecimento e do Programa de Pós-Graduação em Ciência da Informação na Universidade Federal de Santa Catarina.

http://dx.doi.org/10.1590/1981-5344/2417

O artigo aborda o uso da informação para tomada de decisão em gestão de pessoas de gestores de agências bancárias. Os objetivos específicos são (i) identificar os canais e as fontes de informação utilizadas; (ii) identificar as principais barreiras enfrentadas; (iii) descrever os usos das informações do sistema de informação gerencial desenvolvido pela empresa; (iv) verificar a qualidade percebida pelos gestores em relação ao sistema de informação gerencial. A pesquisa é do tipo estudo de caso, realizou-se com gestores de agências bancárias no estado de Santa Catarina e se obtiveram 273 gestores respondentes. A análise do uso da informação foi verificada sob três categorias: (i) canais e fontes de informação; (ii) barreiras de acesso à informação; (iii) sistemas de informação gerencial. Os resultados revelam que os canais e fontes internas formais são os preferidos pelos gestores: normativos internos (95\%), Intranet (91\%) e Informativos internos (73\%). As barreiras de acesso à informação mais enfrentadas pelos gestores foram sobrecarga informacional $(67 \%)$ e falta de tempo $(62 \%)$. O sistema de informação desenvolvido pela 
instituição bancária foi analisado e avaliado pelos gestores do banco. Conclui-se que os gestores precisam de muita informação para a tomada de decisão e esta informação é encontrada no âmbito interno da instituição bancária.

Palavras-chave: Uso da informação. Instituição Bancária. Tomada de decisão gerencial. Gestão de Pessoas.

\section{Analysis information use for decision making in management person: case study in a bank}

The article examines the information use for decision making on personnal management. The specific objectives are: (i) identify the channels and sources of information, (ii) identify the barriers when seeking access to information (iii) describe the uses of information within a management information system developed by a company (iv) to verify the quality perceived by managers of a management information system. The research is a case study and investigated 273 managers of branches bank on Santa Catarina, Brazil. The analysis of the information was verified about three categories: (i) channels and sources of information, (ii) Barriers to access to information, (iii) Management information systems. The results shows that the internal formal channels and sources are the more used by managers, as internal rules and procedures (95\%), Intranet (91\%) Internal information (73\%). Barriers to access information faced by managers were the information overload $(67 \%)$ and lack of time (62\%). The information system developed by company was analyze and evaluate by the managers of the bank. Finally, the analysis showed that managers need a lot of information for decision-making and this information is found within the bank.

Keywords: Information use. Banking Industry. Decision making. Persons Management.

Recebido em 05.05.2015 Aceito em 12.07.2017

\section{Introdução}


A tomada de decisão gerencial é um processo cotidiano nas organizações e intensivo em informação (CHOO, 2006; CALLE, 2008; MORESI, 2000). Os gestores, para direcionar as equipes de trabalho, precisam constantemente tomar decisões e tem-se como maior desafio alimentar os processos decisórios com informações precisas, de qualidade e, ainda, saber como utilizá-las para ter uma boa prática de gestão. Para Lira et al. (2007), os tomadores de decisões frequentemente trabalham com grande quantidade de dados em estado bruto, com pequena quantidade de informação com valor agregado e pouco conhecimento adquirido para a tomada de decisão.

Estudar os fluxos informacionais, com enfoque no uso da informação para tomada de decisão, contribui para entender como, onde e para qual finalidade a informação é utilizada nas organizações. Borges (1995) considera que para as decisões serem tomadas de forma eficaz é necessário que se tenha conhecimento de onde buscar a informação relevante à organização.

Os indivíduos a utilizam a informação para responder a uma questão, solucionar um problema, tomar uma decisão, negociar uma posição ou dar sentido a uma situação; o uso da informação acarreta a mudança do estágio cognitivo e capacidade de agir das pessoas ( $\mathrm{CHOO}$, 2006). Por isso, é relevante saber como o fluxo de informação ocorre e quais os canais de informação são utilizados pelos usuários.

A sobrevivência das organizações depende da habilidade de gerir as informações e gerar conhecimento aos executivos ou gestores nas tomadas de decisão. A partir do entendimento dos fluxos informacionais, é possível desenvolver ações de melhorias que diretamente se relacionam ao sucesso do processo decisório e, consequentemente, ao sucesso empresarial. Na visão de Choo (2006), o sucesso do processo decisório depende de um conjunto de variáveis como a quantidade e qualidade da informação utilizada e a capacidade cognitiva do tomador de decisões.

Este artigo foi pautado em pesquisa sobre o da informação na tomada de decisão gerencial em gestão de pessoas. Como delimitação, optou-se por realizar em uma instituição bancária, pois se entende que nela exista uma grande diversidade de informações e tomadas de decisão gerencial passíveis de serem exploradas. Além do mais, a instituição em questão desenvolveu um sistema de informações gerenciais com 0 objetivo de oferecer informações relacionadas à gestão de pessoas para serem utilizadas como subsídios na tomada de decisão pelos gestores.

Espera-se que o assunto estudado colabore com a Ciência da Informação, fornecendo elementos ainda pouco abordados sobre o uso da informação no contexto do setor bancário e traga subsídios concretos para trabalhos futuros da área da gestão da informação. Ainda assim, tem-se a hipótese de que elementos observados na instituição bancária em questão possam contribuir para a gestão empresarial de outras empresas ou unidades de informação.

\section{Problemática}


Muitas organizações desconhecem os mecanismos e estruturas do fluxo da informação e acabam por não gerenciá-lo de forma eficaz. A falha na disponibilidade das informações potencializa o envio de informações incompletas e o estabelecimento de tomadas de decisões não assertivas.

Nesse contexto, surgiram dúvidas relacionadas ao fluxo da informação na tomada de decisão gerencial quanto à área de gestão de pessoas de determinada instituição bancária, de saber como estas informações se tornam úteis aos usuários e quais os atributos de qualidade são relacionados a elas. Não se tinha clareza de que tipo de fontes e quais os canais os gestores utilizavam para a tomada de decisão e se os esforços da instituição em desenvolver um sistema com informações para apoiar as decisões era útil aos usuários. Assim, emergiu a pergunta que orientou a construção da pesquisa: Quais as fontes e canais são consultados para a tomada de decisão gerencial em gestão de pessoas e quais as finalidades e atributos os tomadores de decisão de uma instituição bancária reconhecem (percebem) no sistema de informações gerenciais desenvolvido pela empresa?

\section{Objetivos}

O objetivo geral da pesquisa é analisar o uso da informação no processo de tomada de decisão gerencial em gestão de pessoas em uma instituição bancária. Para atingir o propósito geral, delimitaram-se os seguintes objetivos específicos:

a) identificar os canais e fontes informação utilizados pelos gestores de agências bancárias;

b) identificar as principais barreiras enfrentadas na busca e no acesso às informações;

c) descrever os usos das informações do sistema de informação gerencial desenvolvido pela empresa;

d) verificar a qualidade percebida pelos gestores em relação ao sistema de informação gerencial desenvolvido pela empresa.

\section{Procedimentos metodológicos}

A unidade de análise foi uma instituição bancária brasileira. Diante das particularidades desse tipo de empresa, assim como da natureza do seu escopo de trabalho, infere-se que nela exista uma gama de informação utilizada pelos gestores nas mais diversas situações. A instituição em questão desenvolveu um sistema de informação com dados e relatórios gerenciais que foram disponibilizadas aos funcionários, sendo este objeto de estudo da pesquisa.

A população-alvo foi o grupamento de 1.697 gestores das unidades de negócios (agências) do estado de Santa Catarina, Brasil. Optou-se pelos gestores que atuam nas unidades de negócios (agências), tendo em 
vista que são estes que desenvolvem, mais diretamente, a atividade fim da empresa.

Utilizou-se o questionário como instrumento de coleta dos dados. 0 questionário é um dos procedimentos mais usuais para obtenção de informações em pesquisas científicas, pois se constitui de um meio rápido e mais barato para obtenção de informações, além de não exigir treinamento de pessoal, bem como assegura o anonimato (GIL, 2010).

O questionário desenvolvido continha 19 perguntas dispostas em quatro módulos. O primeiro módulo - Caracterização do correspondente - buscou conhecer aspectos referentes aos respondentes como: sexo, faixa etária, escolaridade, região, nível gerencial; no segundo módulo - Canais e fontes utilizadas - objetivouse identificar os canais e as fontes utilizados pelos gestores em suas tomadas de decisão em gestão de pessoas a fim de entender o contexto decisório dos gestores na organização. No terceiro módulo - Barreiras de acesso à informação - mapearam-se as principais dificuldades dos gestores em relação ao acesso à informação e no quarto e no último módulo - Sistema de Informação Gerencial - enfocaram-se as questões relacionadas à tecnologia de informação gerencial desenvolvida pela empresa e buscou entender a percepção dos gestores em relação aos atributos de qualidade e as finalidades de uso da ferramenta. Ao final do questionário, disponibilizou-se um campo para outras informações e observações a fim de que se o respondente considerasse necessário, poderia beneficiar-se.

\section{Procedimentos éticos}

Alinhados aos princípios éticos da pesquisa científica manteve-se em sigilo o nome da instituição pesquisada, sendo essa identificada simplesmente por "instituição bancária". Os nomes dos respondentes também foram preservados, não sendo identificados quaisquer dados que possam revelá-los, bem como se omitiu o nome do sistema de informação gerencial, desenvolvido pela empresa, a fim de preservar a identidade da instituição foco do estudo. A pesquisa tem a autorização da área subordinante do assunto da instituição bancária.

\section{Análise dos resultados}

Disponibilizou-se o questionário aos respondentes de forma on-line por intermédio de ferramenta especializada do sistema GoogleDocs no período de 15/03/2013 a 15/04/2013. Os gestores público-alvo receberam as orientações e o hiperlink para acesso ao questionário. 273 gestores responderam ao questionário, percentual de $16 \%$ de respondentes em relação ao público total. A quantidade de respondentes considera-se adequada supondo uma confiança de $94,5 \%$ dos dados, erro amostral 5,5\%, de acordo com os critérios de Barbetta (2011), figura 1. 
Figura 1 - Erro amostral
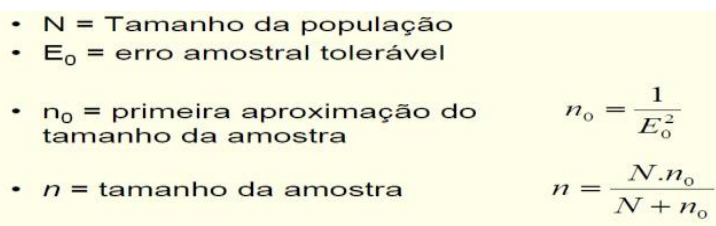

Fonte: BARBETTA (2011).

Trata-se de uma pesquisa do tipo "estudo de caso", portanto os resultados são válidos para a população-alvo da instituição pesquisada.

\subsection{Caracterização dos respondentes}

A fim de caracterizar a amostra de respondentes, no primeiro bloco do instrumento de coleta dos dados, solicitaram-se as informações como gênero, escolaridade, funções exercidas, nível e regional de localização da agência em que trabalha. Estas informações são relevantes para traçar o perfil dos respondentes, conhecer as particularidades do público e confirmar a qualidade da amostra.

Gênero - em relação ao gênero, foram $72 \%$ de respondentes homens (196) e 28\% mulheres (77). A amostra mostrou-se com proporção semelhante à distribuição de gênero da população-alvo, que é de $69 \%$ gestores homens e $31 \%$ gestoras.

Faixa Etária - a faixa etária dos respondentes foi diagnosticada e revelou que $17 \%$ (46) de gestores tem idade entre 20 a 30 anos, $41 \%$ (112) com 31 a 40 anos, 29\% (78) de 41 a 50 anos e 13\% (37) com mais de 50 anos.

Escolaridade - quanto ao grau de escolaridade, a caracterização indicou que $94 \%$ dos gestores (257) tem pelo menos escolaridade de graduação, sendo que $66 \%$ são Pós-Graduados; $28 \%$ possuem apenas a graduação; e 6\% Ensino Médio.

Funções exercidas - a amostra foi composta por 39\% (107) Gerentes de Relacionamento; 24\% (66) Gerentes de Serviços; 20,5\% (56) Gerentes Gerais; 9\% (24) Gerente de Módulo; 6\% (16) Gerente de Negócios; $1 \%$ (3) Gerentes de Segmentos e 0,5\% (um) Gerente de Setor. Quando comparada a amostra com a população alvo, verificou-se que houve um percentual menor de respondentes da função "Gerente de Relacionamento". A natureza do trabalho dos Gerentes de Relacionamento é a comercialização em carteiras negocial (pessoa física ou jurídica) e, por esse motivo, alguns não têm equipe de subordinados o que se pode inferir que não se sentiram instigados a responder ao questionário, que se trata sobre tomada de decisão em gestão de pessoas. Em contrapartida, o percentual dos "Gerentes de Serviço" da amostra para a população alvo foi ligeiramente superior, haja vista que são gerentes que atuam no apoio 
a serviços administrativos da unidade, em grande parte ligados à administração de pessoal.

Nível e Localização da agência - em se tratando ao nível da agência em que atuam, os dados revelaram maior concentração de respondentes das agências nível 3 - agência em média 20 funcionários. Quanto à regional de localização $26 \%$ dos respondentes (71) estão na Regional Florianópolis, $21 \%$ (58) na Regional Joinville, $17 \%$ (47) na Regional Blumenau, 14\% (38) na Regional Chapecó, 13\% (36) na Regional Criciúma e $8 \%$ (23) na Regional Lages.

A amostra revelou-se em conformidade aos procedimentos metodológicos e distribuída adequadamente às características da população alvo.

\subsection{Canais e fontes de informação}

Solicitou-se então, primeiramente, que os gestores apontassem o quanto de informações, na opinião deles, são necessárias para desenvolver as atividades de gestão na agência bancária. Para isto, disponibilizou-se a possibilidade de indicar, dentro de uma escala de 1 a 5 , a quantidade de informação necessária, quanto mais perto do 1 considera-se pouca informação e mais próximo do 5, muita informação. Quase que a totalidade dos respondentes, 97\%, 264 respondentes sinalizaram na escala de 4 e 5, podendo-se considerar que os gestores utilizam muita informação para tomar as decisões. Este resultado corrobora com as afirmações de Choo (2006), Calle (2008) e Borges (1995) que dispõem que o processo decisório é acentuado em informação.

Em relação aos canais e fontes de informação, solicitou-se a frequência de utilização das fontes e canais no apoio à tomada de decisão, qualificando-as em externas e internas. A frequência de utilização foi diagnosticada com o auxílio da escala Likert, selecionando a frequência de utilização (1) nunca; (2) raramente; (3) às Vezes; (4) com frequência; (5) sempre.

Os canais e fontes internas são os mais utilizadas pelos gestores, destacando os normativos internos, a Intranet e os informativos internos. Das fontes externas, destacaram-se a internet, informativos, jornais e revistas. Kraaijenbrink (2007) afirma que a Internet (web) é um importante ambiente para busca de informação. As fontes e canais externos menos utilizados pelos gestores para apoio à tomada de decisão foram: "Entidades Sindicais" e "Gestores da Concorrência".

Identificou-se que os recursos formais são os mais utilizados pelos gestores. De acordo com Cunha (2001), canal e fonte formal é "o local onde as informações são registradas e disseminadas de forma impressa ou eletrônica, por meio das fontes primárias e secundárias". Mediante a inerência do trabalho bancário, de atuar no mercado financeiro, com risco, mercado suscetível a fraudes, os tomadores de decisão da instituição declaram buscar informações para apoiar as tomadas de decisão nos recursos formais de comunicação. Infere-se que esta situação decorre da 
cultura organizacional da instituição bancária de pautar-se em normas e regras definidas.

As fontes informais também foram citadas, tais como: os "superiores", "subordinados" e "pares". Estes dados revelam que existe a troca de informações entre as pessoas como apoio à tomada de decisão em gestão de pessoas. A consulta aos pares, em frequência de $97 \%$ (265 apontamentos), diagnostica que, durante o processo de tomada de decisões, o gestor se utiliza dos conhecimentos e experiências dos colegas para agregar informação à sua decisão. A consulta aos subordinados (87\%, 238 apontamentos) caracteriza que os funcionários são consultados quando as decisões são tomadas, o que pode representar que as decisões em gestão de pessoas são compartilhadas e existe o caráter participativo dos funcionários. Além do mais, a consulta aos pares na busca de informações para tomada de decisão, evidencia a hipótese que a instituição bancária promova a tomada de decisão em comitê, com compartilhamento de ideias e opiniões entre gestores.

\subsection{Barreiras de acesso à informação}

As barreiras de acesso à informação constituem outra categoria de análise da pesquisa. Buscou-se, portanto, inserir ao questionário perguntas que pudessem identificar as dificuldades enfrentadas pelos gestores no acesso à informação.

A partir disso, solicitou-se aos respondentes a frequência de dificuldades no acesso à informação a partir de oito situações previamente definidas por Curty (2005).

Quadro 1 - Barreiras de acesso à informação

\begin{tabular}{l}
\hline \multicolumn{1}{c}{ BARREIRAS DE ACESSO Á INFORMAÇÃO } \\
\hline \hline Grande variedade de fontes de informação (sobrecarga informacional) \\
\hline Indisponibilidade de tempo para a busca de informação \\
\hline Não integração dos sistemas de informação organizacionais \\
\hline Dificuldade de localização \\
\hline Demora na obtenção de documentos; \\
\hline Material insuficiente e/ou desatualizado \\
\hline Obsoletismo e/ou insuficiência das tecnologias \\
\hline Linguagem (jargões/terminologia desconhecidos) \\
\hline Fonte: Adaptado de CURTY (2005).
\end{tabular}

As principais barreiras de acesso às informações enfrentadas pelos gestores são "Sobrecarga Informacional" e "Falta de Tempo". De acordo com o autor Startec (2002), um dos maiores paradoxos dos dias de hoje é justamente encontrar a informação relevante no mar de informações disponíveis. Assim, a sobrecarga de informação vivenciada pelos gestores é decorrente da grande variedade de fontes de informação disponíveis no contexto interno e externo da instituição. Considerando que os gestores 
se servem mais das fontes e canais internos, infere-se que existe na instituição bancária uma diversidade de canais e fontes disponíveis.

A falta de tempo é o outro aspecto identificado na pesquisa. A grande variedade de fontes e os canais de informações (sobrecarga informacional) atrelados à falta de padronização contribuem para se ter a percepção da "indisponibilidade de tempo" como barreira para acesso à informação. A figura 2 mostra que as barreiras de acesso à informação podem se relacionar:

Figura 2 - Barreira de acesso à informação

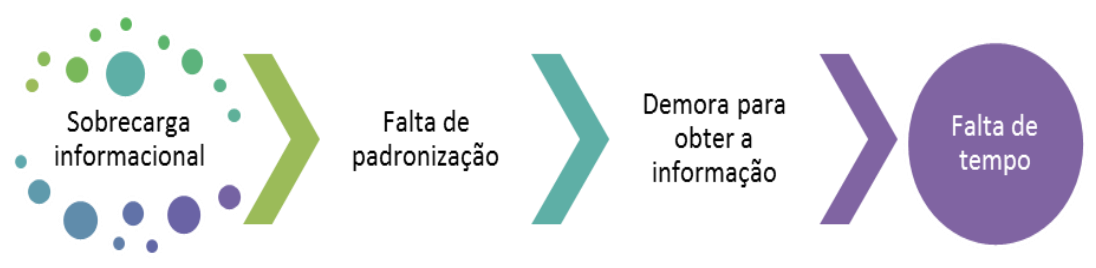

Fonte: Dados da pesquisa.

Quando se tem uma gama de informações presa a falta de padronização e a demora para se obter a informação, mais esforços e tempo são necessários para se alcançar a informação desejada. Cabe destacar que os aspectos "Falta de padronização" e "demora para se obter a informação" foram barreiras diagnosticadas por meio da pergunta aberta do questionário.

Os aspectos menos relacionados como barreiras foram a "linguagem", "obsoletismo dos mecanismos tecnológicos" e "materiais desatualizados". Acredita-se que nestes aspectos, a instituição, dentro da gestão da informação, busca previamente identificar e sanar com o obséquio de minimizar o esforço dos gestores no processo de busca da informação.

Não obstante, tendo em vista o diagnóstico de que os canais e fontes internos são aqueles mais utilizados, a barreira da linguagem é pouco enfrentada. A informação interna é fornecida pela empresa de acordo com a linguagem culturalmente reconhecida (jargões, termos, siglas, símbolos entre outros). Situação diferente poderia ocorrer se a informação mais significativa fossem as externas.

O obsoletismo e/ou insuficiência das tecnologias não demostraram barreiras de acesso à informação para parte da população alvo (52\%, 141 apontamentos), no entanto $37 \%$ dos gestores (102 apontamentos) consideram que "às vezes" enfrentam essa situação. Partindo do pressuposto que as principais fontes utilizadas pelos gestores estão disponíveis em canais digitais, a inconstância das tecnologias ou até mesmo a indisponibilidade momentânea das tecnologias da informação podem ser barreiras a ser enfrentadas para o acesso à informação. 
O diagnóstico das barreiras de acesso à informação possibilita entender o contexto da instituição e verificar as possibilidades de melhoria do processo de comunicação e da gestão da informação.

A seguir será analisado os dados referentes ao Sistema de Informação Gerencial desenvolvido pela empresa, aspectos de sua apresentação, atributos de qualidade e uso na tomada de decisão.

\subsection{Sistema de informação gerencial}

A pesquisa abordou aspectos relacionados a um Sistema de Informação Gerencial desenvolvido para apoio à tomada de decisão dos gestores. O sistema em questão foi lançado em 2012 pela diretoria de Gestão de Pessoas da instituição bancária e tem por objetivo oferecer informações gerenciais por meio de relatórios, gráficos e séries históricas de indicadores de gestão de pessoas. Pelo sistema é possível acompanhar os dados e informações relacionados a agência, com auxílio de gráficos e indicadores, identificando oportunidades para o aprimoramento dos processos de gestão de pessoas de cada unidade (agência). Na figura 3 a seguir é demonstrado a sistemática de informações do sistema.

Figura 3 - Sistema de Informação Gerencial

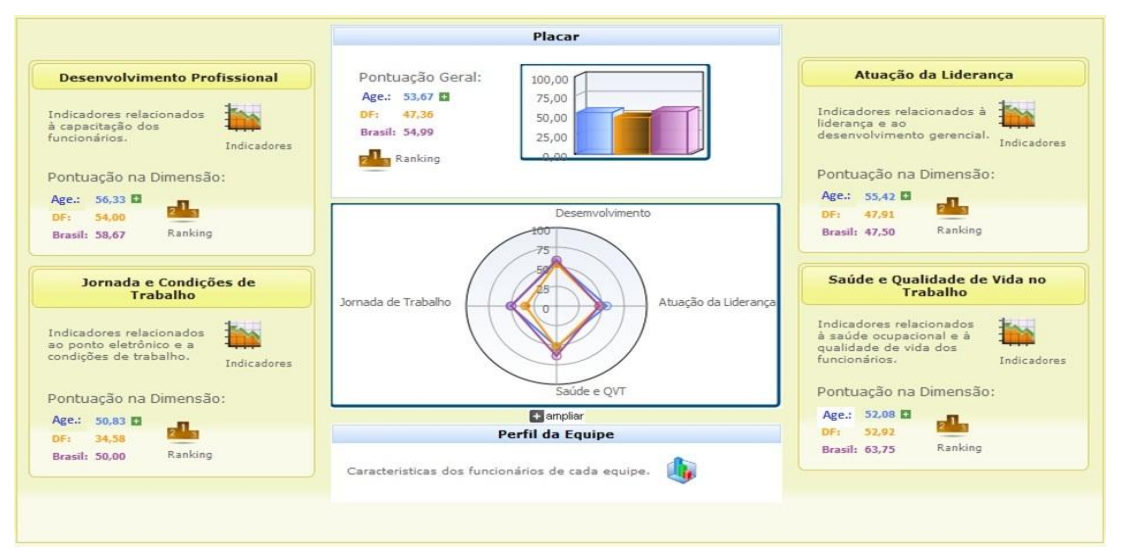

Fonte: Dados da pesquisa.

Os indicadores são classificados em cinco dimensões: Desenvolvimento Profissional, Atuação da Liderança, Saúde e Qualidade de Vida, Jornada e Condições de Trabalho, e Perfil da Equipe. Cada dimensão possui uma série de indicadores e relatórios relacionados:

a) desenvolvimento profissional: indicadores relacionados a ações de desenvolvimento pessoal e profissional, que visam acompanhar a distribuição e realização das ações de capacitação oferecidas pela Empresa para a consecução dos objetivos organizacionais;

b) atuação da liderança: indicadores relacionados ao estilo de gestão, características apresentadas pelos gestores quanto à gestão de suas equipes, relacionamento interpessoal e desenvolvimento de competências gerenciais; 
c) jornada e condições de trabalho: indicadores relacionados a trabalho extraordinário e condições de trabalho, além do acompanhamento do ponto eletrônico;

d) saúde e qualidade de vida no trabalho: indicadores relacionados a ações, processos e ocorrências referentes à saúde ocupacional e à qualidade de vida no trabalho dos funcionários;

e) perfil da equipe: indicadores relacionados ao perfil dos funcionários, como formação superior, tempo de banco, tempo na unidade, rotatividade de pessoas e diversidade de gênero.

O sistema permite que os gestores acompanhem o comportamento da agência, comparando a sua agência com as outras unidades, como por exemplo: agências do mesmo nível (estado e país), todas as agências do estado, todas as agências do país.

Figura 4 - Radar comparativo entre unidades
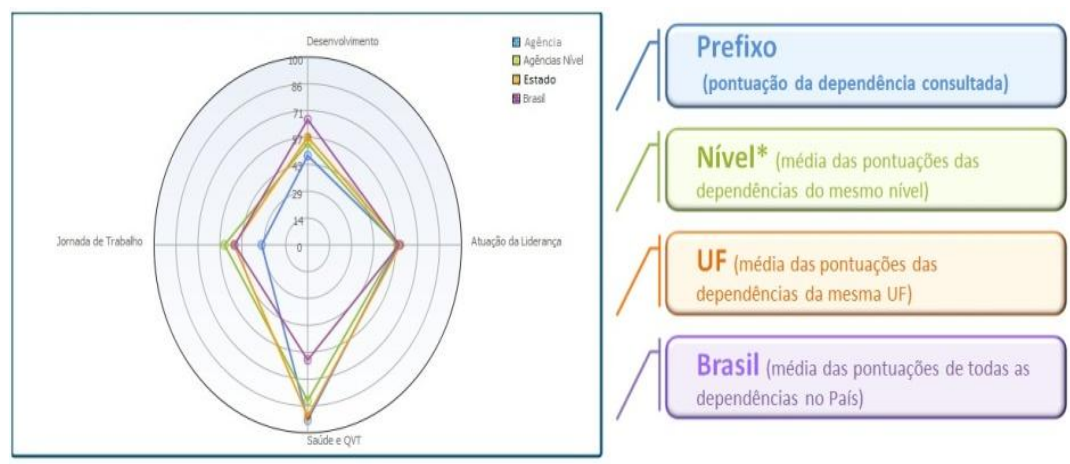

Fonte: Dados da pesquisa.

Sendo assim, para fins de cumprir com os objetivos específicos "c" e "d", buscou-se identificar os gestores que conhecem e utilizam a ferramenta a fim de descrever o uso das informações do sistema e verificar a qualidade percebida por eles em relação a ela. Por serem gestores que conhecem e manipulam diretamente as informações do sistema desenvolvido, são considerados os mais adequados a fornecerem um diagnóstico perceptivo da qualidade da informação disponibilizada bem como a finalidade (funcionalidade) na empresa. Assim, participaram desta etapa 135 respondentes que assinalaram a opção "sim" na questão "você conhece o sistema de informação?".

\section{Atributos}

O atributo mais citado pelos gestores foi credibilidade (55\%, 73 apontamentos), seguido de acessibilidade (53\%, 71 apontamentos), 
entendimento (47\%, 63 apontamentos) e clareza $(47 \%, 63$ apontamentos). Os atributos menos reconhecidos foram "completeza" (16\%, 21 apontamentos) e "precisão" (11\%, 15 apontamentos).

Trindade, Oliveira e Becker (2011) afirmam que "credibilidade" é a informação considerada verdadeira e confiável. Por ser um sistema desenvolvido pela empresa, ou seja, uma fonte de informação interna, existe a confiabilidade dos gestores em relação às informações ali disponíveis. A "acessibilidade", definida por "os dados tem recuperação fácil e segura" foi o segundo atributo mais citado. Este atributo pode-se relacionar ao fato de a ferramenta estar sempre disponível no ambiente Intranet da instituição bancária, passível de ser consultado frequentemente.

O atributo "completeza" busca identificar se o sistema provê toda a informação necessária para a execução da atividade e 0 atributo "precisão" define se a informação está ao nível de detalhe para o uso a qual se destina. Estes atributos foram os menos citados pelos gestores. Assim, tomando as afirmações de Choo (2006), Calle (2008) e Borges (1995) que o processo decisório é intensivo em informação, corroborados pelos dados empíricos desta pesquisa, entende-se que, apesar de a ferramenta reunir uma diversidade de informações, outras fontes de informação também são consultadas pelos gestores para busca de informações, como: os Normativos Internos, e as fontes informais dos Pares, Subordinados e Superiores.

Quando questionado aos gestores se o sistema contribui pouco ou muito para a assertividade do processo decisório, os dados evidenciam que o sistema contribui para as atividades de gestão; com exceção de 11 gestores $(8 \%)$ que assinalaram o contrário.

\section{Finalidades de uso das informações}

Buscou-se analisar usos da informação do sistema de informação gerencial de acordo com situações decisórias descritas pelos gestores. Assim, questionou-se aos gestores se já haviam utilizado o sistema para tomada de decisão. Em vista disso, 48 gestores indicaram que já tomaram alguma decisão com o uso das informações do sistema, sendo que destes, 35 contribuíram com a pesquisa e descreveram brevemente a situação decisória.

Mediante o procedimento metodológico as situações vivenciadas pelos gestores foram classificadas de acordo com as classes de finalidade de uso da informação de Taylor (1991). Esta etapa mostrou-se importante para identificar os usos da ferramenta e as tomadas de decisão em nível de gestão de pessoas.

As situações decisórias relatadas pelos gestores caracterizam-se por um extrato das atividades de gestão de pessoas na instituição bancária. De acordo com os dados apresentados, os gerentes-gerais foram aqueles que mais contribuíram com situações de uso do sistema e foram eles que, segundo dados da pesquisa, mais utilizaram a ferramenta. 
As classes de finalidade de uso das informações evidenciadas foram: "Pessoal ou Política" (13 situações), "Projetiva" (12 situações), Motivacional (4 situações), Esclarecimento (3 situações), Factual (2 situações) e Confirmativo (uma situação). Não houve situações decisórias compatíveis com as categorias "Instrumental" e "Compreensão de problemas".

O sistema de informação gerencial desenvolvido pela instituição bancária tem o propósito de oferecer diagnóstico das agências bancárias para oportunizar o aprimoramento das práticas de gestão de pessoas. Sendo assim, ressaltamos a finalidade "Projetiva" que vislumbra a leitura de cenários e planejamento do futuro e a finalidade "Pessoal ou Política" que é definida pelo uso da informação para criar relacionamentos e promover a melhoria de status e reputação pessoal, são finalidades que convergem com o propósito pelo qual a ferramenta foi desenvolvida. A primeira, por utilizar os dados e informações disponíveis para projetar e planejar ações estratégicas à unidade; e a segunda por permitir que a partir das informações ali expostas seja possível manter ou buscar a melhoria do status e reputação mediante a comparação com o resultado de outras unidades (agências) da instituição.

Além do mais, a utilização dos indicadores, relatórios e gráficos do sistema possibilitaram a promoção da integração e motivação dos funcionários, como descrito pelo respondente 54 "busquei o envolvimento da equipe em vista de uma situação que implicaria a melhoria coletiva". Esta situação descreve a utilidade da informação "Motivacional" descrita por Taylor (1991).

O envolvimento da equipe na tomada de decisão foi considerada como fundamental pelo respondente 12 em suas observações

"impossível deixar de lembrar a importância da participação da equipe na tomada de decisão, pois o tamanho do comprometimento é proporcional ao da participação [...] o comportamento em prol da decisão a respeito de gestão de pessoas não pode ser apenas do tomador da decisão, independente de ser o gestor ou não, mas de toda a equipe."

Por tratar de decisão em nível de gestão de pessoas, a participação e envolvimento da equipe na decisão é importante.

Aspectos de mudança de comportamento também foram apontados, como descrito pelo respondente 193

"utilizei o sistema para avaliar o desempenho geral da agência nas perspectivas avaliadas e, consequentemente, planejar ações para melhoria do desempenho.".

Assim, considera-se que o sistema, além de servir como uma fonte de informação atua como ferramenta que instiga a ação de melhoria dos processos de gestão de pessoas.

Em relação aos processos de gestão de pessoas evidenciados nas situações decisórias descritas pelos gestores, observou-se relacionamento com: capacitação e desenvolvimento dos funcionários; gestão do clima 
organizacional; e aprimoramento das práticas de gestão da dependência e ações estratégicas para atingir as metas da unidade. Nessas condições, mesmo não identificando por completo os atributos "completeza" e "precisão", os gestores depositam "credibilidade" ao sistema haja vista que utilizaram para fazer planejamentos, planos de ação, motivar a equipe, diagnosticar cenário da agência e buscar melhorias do clima organizacional.

\section{Considerações finais}

A pesquisa partiu do pressuposto que existem nas instituições bancárias uma diversidade significativa de informações. Esta premissa foi confirmada quando diagnosticado a necessidade de elevada quantidade de informação para tomada de decisão, acrescidas pela nuance que essas informações são encontradas, principalmente, em canais e fontes internas da instituição. Neste contexto, conclui-se que o processo decisório é intensivo em informação e que os gestores da instituição bancária necessitam de um volume significativo de informações para o apoio às decisões relacionadas a gestão de pessoas e essas são encontradas no âmbito interno da instituição bancária. O instrumento de coleta dos dados e os procedimentos metodológicos se mostraram apropriados para diagnóstico do uso da informação para tomada de decisão. As categorias de análise do questionário trouxeram subsídios para entender onde os gestores buscam informações, quais as dificuldades percebidas no processo e como é utilizado o sistema de informação gerencial desenvolvido pela empresa.

Assim, e de acordo com os objetivos propostos, considera-se que as fontes e canais internos são aqueles mais utilizados pelos gestores para tomada de decisão em nível de gestão de pessoas e existe a preferência pelas fontes e canais formais. Na instituição bancária, há interação entre as pessoas na busca de informações para tomada de decisão em gestão de pessoas, refletida na consulta às fontes informais internas "pares", "subordinados" e "superiores". A falta de tempo e a sobrecarga de informação são as principais barreiras de acesso à informação enfrentadas pelos gestores. Entretanto, ao mesmo tempo em que os gestores entendem que há sobrecarga informacional também consideram que o processo decisório é intenso em informação. Assim, compreende-se que os tomadores de decisão precisam ter a habilidade de lidar com as informações que recebem e trabalhar no propósito de inferir e considerar apenas aquelas que lhe são necessárias. O sistema de informação gerencial desenvolvido pela empresa advém da necessidade de reunir em uma ferramenta informações que estavam dispersas em diversas fontes e canais internos.

Os gestores utilizaram o sistema de informação gerencial para alcançar o envolvimento e motivação dos funcionários desenvolvendo planos de trabalho para melhoria das práticas de gestão de pessoas nas agências. A ferramenta gerencial desenvolvida é uma forma 
diferenciada de fonte de informação, pois além de trazer informações sobre gestão de pessoas, agrega em sua funcionalidade a possibilidade de diagnosticar as equipes e equalizar os processos de gestão de pessoas na empresa, pois compara os resultados de uma unidade com as demais. Considera-se, assim, que é uma tecnologia de informação passível de contribuir no processo de gestão empresarial e de ser replicada em outras organizações.

Por fim, a gestão da informação é aspecto essencial para a melhoria da gestão empresarial. O diagnóstico do uso da informação para tomada de decisão em gestão de pessoas na instituição bancária trouxe subsídios relevantes para entender como e quando as informações se tornam úteis aos usuários de informação. Os dados revelam situações particulares da instituição bancária passíveis de serem consideradas pelos gestores de informação em eventuais ações de planejamento dos processos de trabalhos em outras empresas. Espera-se que o método, resultados e considerações deste estudo de caso possam contribuir de forma instrutiva com a literatura da área da gestão e fluxo da informação e propiciar que novos estudos sobre o tema sejam desenvolvidos.

\section{Referências}

BARBETTA, P. A. Estatística aplicada às ciências sociais. 7. ed. Florianópolis: Ed. da UFSC, 2011.

BORGES, M. E. N. A informação como recurso gerencial das organizações na sociedade do conhecimento. Ciência da Informação, Brasília, v. 24, n. 2, p. 181-188, maio/ago. 1995. Disponível em: <http://revista.ibict.br/ciinf/index.php/ciinf/article/view/551/500>. Acesso em: 25 jan. 2013.

CALLE, G. A. Fluxos de informação como suporte à tomada de decisões: um modelo de análise. 2008. 151f. Dissertação (Mestrado em Ciência da Informação) - Programa de Pós-Graduação em Ciência da Informação. Universidade Federal de Santa Catarina, Florianópolis, 2008.

CHOO, C. W. A organização do conhecimento. São Paulo: Senac, 2006.

CUNHA, M. B. da. Para saber mais: fontes de informação em ciência e tecnologia. Brasília: Briquet de Lemos, 2001. 168 p.

CURTY, R. G. O fluxo da informação tecnológica no projeto de produtos em indústrias de alimentos. 2005. 246 f. Dissertação (Mestrado em Ciência da Informação) - Programa de Pós-Graduação em Ciência da Informação, Centro de Ciências da Informação. Universidade Federal de Santa Catarina, Florianópolis, 2005.

GIL, A. C. Como elaborar projetos de pesquisa. 5. ed. São Paulo: Atlas, 2010. 159 p.

KRAAIJENBRINK, J. Engineers and the Web: an analysis of real life gaps in information usage. Information Processing and Management, v. 43, p. 
1368-1382, 2007.

Disponível

em: <http://dl.acm.org/citation.cfm?id=1241316>. Acesso em: 23 jan. 2013. LIRA, W. S. et al. A busca e o uso da informação nas organizações. Perspectivas em Ciência da Informação, Belo Horizonte, v. 12, n. 2, p. 6480, maio/ago. 2007. Disponível em:

MORESI, E. A. D. Delineando o valor do sistema de informação de uma organização. Ciência da Informação, Brasília, v. 29, n.1, p. 14-24, jan./abr. 2000. Disponível em: <www.scielo.br/pdf/ci/v29n1/v29n1a2.pdf >. Acesso em: 25 jan. 2013.

STAREC, C. Informação e Universidade: os pecados informacionais e barreiras na comunicação da informação para a tomada de decisão na universidade. DataGramaZero - Revista de Ciência da Informação, v. 3, n. 4, ago. 2002. Disponível em: <http://www.dgz.org.br/ago02/Art_04.htm\#NOTAS24>. Acesso em: 23 jan. 2013.

TAYLOR, R. S. Information use environments. In: DERVIN, B.; VOIGT, M. J. (Orgs). Progress in communication sciences. Norwood, NJ: Ablex Publishing, 1991. p. 217-254. 